\title{
NOTES
}

\section{Synthesis and Conformational Study of Poly(D-p-hydroxy- phenylglycine) and Its Benzyloxycarbonyl Derivative}

\author{
Tadao Hayakawa, Katsuhiko Inouye, Atsushi Matsuzaki, \\ and Hiroyuki YAMAMOTO \\ Institute of High Polymer Research, Faculty of Textile Science \\ and Technology, Shinshu University, Ueda 386, Japan
}

(Received August 6, 1984)

\begin{abstract}
KEY WORDS Poly(D- $p$-hydroxyphenylglycine $) \quad / \quad \operatorname{Poly}(O$-benzyloxycarbonyl-D- $p$-hydroxyphenylglycine) / Circular Dichroism / Infrared Spectra / Conformation / $\beta$-to-Coil Transition /
\end{abstract}

Conformational studies on $\operatorname{poly}(\alpha$-amino acids) containing aromatic chromophores in their side chains have been extensively carried out. In these studies, polypeptides containing an aromatic group attached to the $\beta$-carbon atom, such as poly(L-phenylalanine) ${ }^{1}$ poly(Ltyrosine $)^{2}$ and poly(L-tryptophan $)^{3}$ etc., have been used. In a recent paper, Palumbo et al. ${ }^{4}$ reported the synthesis and conformational properties of poly(D-phenylglycine) containing a phenyl group attached directly to the $\alpha$ carbon atom of the amino acid residues. However, this polymer is hardly soluble in water and in most common organic solvents, and physicochemical measurements in solutions are very difficult.

In the present paper, we report the synthesis of and conformational studies on $\operatorname{poly}(O$ benzyloxycarbonyl-D- $p$-hydroxyphenylglycine [poly $(O-\mathrm{Z}-\mathrm{D}-\mathrm{Hpg})]$ and poly(D- $p$ hydroxyphenylglycine) [poly(D-Hpg)], in which the phenyl group is attached to the $\alpha$ carbon atom, so as to clarify the effect of their side chains on the polypeptide structure in organic solvents and in 50\% aqueous methanol solution.

Poly $(O-Z-D-H p g)$ was synthesized by the $N$ carboxyanhydride (NCA) method, and its con- formationl aspects were studied by circular dichroism (CD), infrared absorption spectra (IR) and X-ray diffractions.

$\mathrm{D}-p$-hydroxyphenylglycine is a useful intermediate for the preparation of semisynthetic penicillins and cephalosporins. ${ }^{5,6}$

\section{EXPERIMENTAL}

\section{Materials}

D-p-Hydroxyphenylglycine was purchased from the Sigma Chemical Co. (U.S.A.).

$O, N$-Dibenzyloxycarbonyl-D-p-hydroxyphenylglycine. Dibenzyloxycarbonyl-D-p-hydroxyphenylglycine was prepared by treatment of D- $p$-hydroxyphenylglycine with benzyloxycarbonyl chloride in the usual way at $\mathrm{pH} 9-$ 10. The resultant dibenzyloxycarbonyl derivative was recrystallized from ethyl acetate and $n$-hexane. Yield $62.0 \%, \mathrm{mp} \quad 92^{\circ} \mathrm{C},[\alpha]_{\mathrm{D}}^{25}=$ $-76.0^{\circ}$ (c, 1.0, methanol).

Anal. Calcd for $\mathrm{C}_{24} \mathrm{H}_{21} \mathrm{O}_{7} \mathrm{~N}: \mathrm{C}, 66.20 \% ; \mathrm{H}$, $4.86 \%$; N, 3.22\%. Found: C, $66.34 \% ; \mathrm{H}$, $4.81 \%$; N, 3.34\%.

$O$-Benzyloxycarbonyl-D-p-hydroxyphenylglycine NCA. The above dibenzyloxycarbonyl derivative was treated with thionyl chloride in the usual way. The resultant NCA was ob- 
tained as an oil. Whose solution in dry acetone was passed through a dry charcoalsilver oxide column ${ }^{7}$ and evaporated to dryness. Yield $90.0 \%$. The residual product showed IR absorptions at 1855 and $1785 \mathrm{~cm}^{-1}$ due to cyclic anhydride. The product was used immediately for polymerization.

Poly (O-benzyloxycarbonyl-D-p-hydroxyphenylglycine). The above NCA was polymerized in dioxane using triethylamine as an initiator $(\mathrm{M} / \mathrm{I}=50)$. Yield $85 \%$. The polypeptide showed IR absorptions at 3300, 1765, 1690,1637 , and $1535 \mathrm{~cm}^{-1}$.

Anal. Calcd for $\left(\mathrm{C}_{16} \mathrm{H}_{13} \mathrm{O}_{4} \mathrm{~N}\right)_{n}: \mathrm{C}, 67.83 \%$; $\mathrm{H}, 4.63 \%$; N, $4.95 \%$. Found: C, $67.34 \%$; H, $4.59 \% ; \mathrm{N}, 4.80 \%$.

The polypeptide had an intrinsic viscosity $[\eta]$ of $0.10 \mathrm{dlg}^{-1}$ in dichloroacetic acid (DCA) at $25^{\circ} \mathrm{C}$. The molecular weight was estimated to be $6000\left(D_{p}=20\right)$ from an empirical equation ${ }^{8}$ for $\operatorname{poly}(O$-benzyloxycarbonyl-L-tyrosine $)$ in DCA. Poly $(O-Z-D-H p g)$ was soluble in dioxane, tetrahydrofuran (THF), chloroform, pyridine, trifluoroacetic acid, DCA and insoluble in water.

Poly(D-p-hydroxyphenylglycine). The above $O$-protected polymer was treated with $25 \%$ solution of anhydrous hydrogen bromide in glacial acetic acid. The resultant polymer was purified by reprecipitation with methanol and ether. Yield $50 \%$. The carbonate IR band of the starting polymer at $1765 \mathrm{~cm}^{-1}$ disappeared.

Anal. Calcd for $\left(\mathrm{C}_{8} \mathrm{H}_{7} \mathrm{O}_{2} \mathrm{~N}\right)_{n}: \mathrm{C}, 64.42 \% ; \mathrm{H}$, $4.74 \%$; N, 9.39\%. Found: C, $64.11 \%$; $4.77 \%$; N, $9.06 \%$.

Poly(D-Hpg) was readily soluble in water at $\mathrm{pH}$ above 10.4, and was coagulated at acidic $\mathrm{pH}$. The coagulated polymer was redissolved by adding methanol, ethanol or trifluoroethanol.

\section{Methods}

$\mathrm{CD}$ and IR measurements were performed on JASCO CD J-40A and IR DS-301 instruments, respectively (both made by the
Japan Spectroscopic Co., Ltd.). For CD measurements, the experimental data were expressed in terms of mean residue ellipticity $[\theta]$ (degree $\mathrm{cm}^{2} \mathrm{dmol}^{-1}$ ). X-ray diffraction patterns were photographed with a Rigaku Denki Geigerflex $\left(35 \mathrm{kV}, 25 \mathrm{~mA} \mathrm{Cu} K_{\alpha}\right.$ line $)$.

\section{RESULTS AND DISCUSSION}

The CD spectra of poly $((O-Z-\mathrm{D}-\mathrm{Hpg})$ in dioxane, chloroform and THF were measured. In these solvents, the protected polypeptide showed a negative dichroic band at $225 \mathrm{~nm}$, with $[\theta]_{225}=-3200--4700$. This behavior resembles the $\beta$-conformation of poly(Dphenylglycine) in a water-sulfuric acid $(27: 73$, $\mathrm{v} / \mathrm{v}$ ) mixed solution. ${ }^{4}$

Since poly(D-Hpg) is insoluble in water at $\mathrm{pH}$ below 10, the CD measurements were carried out by changing the $\mathrm{pH}$ in $50 \%$ aqueous methanol. The CD spectra of poly(D$\mathrm{Hpg}$ ) at various $\mathrm{pH}$ are shown in Figure 1. At $\mathrm{pH}$ 4.3, where the aromatic hydroxy groups are unionized, the polypeptide showed a negative dichroic band at $232 \mathrm{~nm}$ with $[\theta]_{232}=-3500$. The position and magnitude

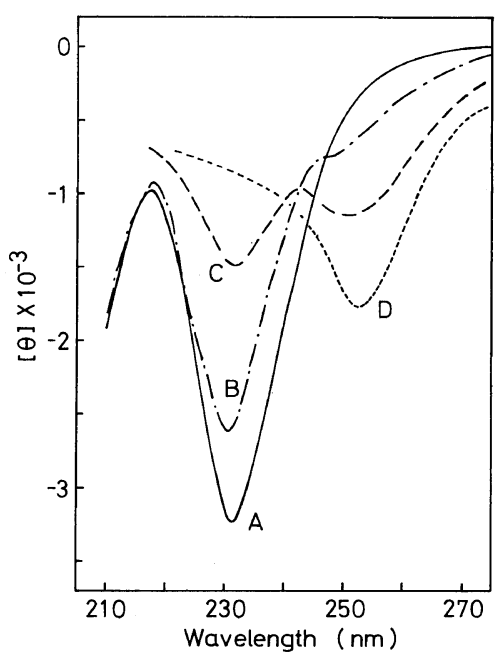

Figure 1. $\mathrm{CD}$ spectra of poly(D-Hpg) in $0.1 \mathrm{M} \mathrm{NaCl} /$ $\mathrm{MeOH}(1: 1, \mathrm{v} / \mathrm{v})$ as a function of $\mathrm{pH}$ at $25^{\circ} \mathrm{C}$. A, (-), $\mathrm{pH} 4.3$; $\mathrm{B},(-\cdot--), \mathrm{pH} 10.1$; $,(----), \mathrm{pH} 10.9 ; \mathrm{D}$, (---), pH 11.5. 
of the dichroic band changed with raising $\mathrm{pH}$. At $\mathrm{pH}$ 11.5, where the aromatic hydroxy groups are ionized, the $232 \mathrm{~nm}$ band disappeared completely and a new negative dichroic band appeared at $254 \mathrm{~nm}$ with $[\theta]_{254}=$ -1800 . Poly(D-Hpg) gave similar CD curves also in water at $\mathrm{pH}$ above 10.4. The CD behavior of poly $(O-Z-D-H p g)$ and poly(D$\mathrm{Hpg}$ ) differed completely from that of an ordered and disordered form of poly(L-lysine) and poly(L-tyrosine) derivatives in aqueous and in organic solvents. ${ }^{9}$

To elucidate the conformation of the protected and unprotected polypeptides, IR spectra and X-ray diffractions were measured in the solid state, and in $\mathrm{NaOD}$ and $\mathrm{CD}_{3} \mathrm{OD} /$ $\mathrm{D}_{2} \mathrm{O}$ solutions. The IR spectra of poly $(O-\mathrm{Z}$-D$\mathrm{Hpg}$ ) film cast from dioxane solution showed absorptions at 1690, 1637 (amide I) and 1532 $\mathrm{cm}^{-1}$ (amide $\left.\mathrm{II}\right)$. At $\mathrm{p} D$ 7, poly(D-Hpg) in $\mathrm{D}_{2} \mathrm{O} / \mathrm{CD}_{3} \mathrm{OD}$ solution also showed absorptions at 1690 and $1630 \mathrm{~cm}^{-1}$ (amide I). Thus, these polypeptides have a $\beta$-conformation with an antiparallel arrangement such as that reported by Miyazawa ${ }^{10}$ and Timasheff et al. ${ }^{11}$ At $\mathrm{p} D$ 12, however, the amide I band of the unprotected polymer was found at $1643 \mathrm{~cm}^{-1}$ and the absorption at $1690 \mathrm{~cm}^{-1}$ disappeared. The absorption at $1643 \mathrm{~cm}^{-1}$ was the same as that observed for randomly coiled poly( $\mathrm{L}^{-}$ lysine) in $\mathrm{D}_{2} \mathrm{O} .{ }^{11}$ The $\mathrm{X}$-ray diffraction photographs of the protected and the unprotected polymers showed a backbone spacing of about $4.6 \AA$ ( $\beta$-conformation), which coincided well with the results of the above IR data. Consequently, $\operatorname{poly}(O-\mathrm{Z}-\mathrm{D}-\mathrm{Hpg})$ may exist as a $\beta$ conformation in helix-promoting solvents and in the solid state. The change in CD spectra of poly $(\mathrm{D}-\mathrm{Hpg})$ on going from $\mathrm{pH} 4.3$ to 11.5 in Figure 1 probably indicates a $\beta$-to-coil transition.

Figure 2 shows plots of ellipticity values at 232 and $254 \mathrm{~nm},[\theta]_{232}$ and $[\theta]_{254}$, respectively, against $\mathrm{pH}$. The changes in the above two parameters are identical, and poly(D-Hpg) un-

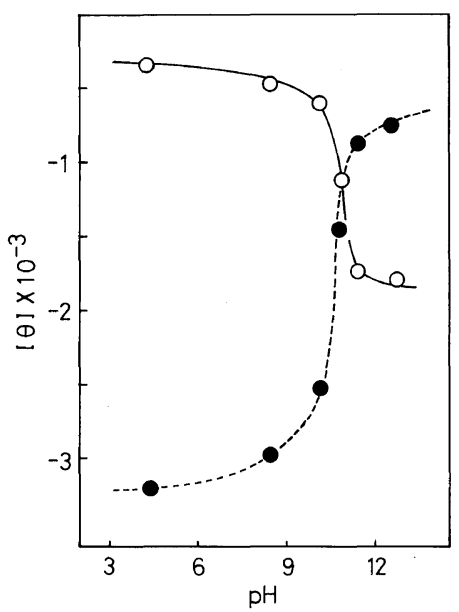

Figure 2. Plots of ellipticities at $232\left(---_{--)}\right.$and $254 \mathrm{~nm}(-\mathrm{O}-)$ of poly(D-Hpg) as a function of $\mathrm{pH}$.

dergoes sharp transition at about $\mathrm{pH}$ 10.5. As in the case of poly(L-tyrosine) ${ }^{2}$ the $\beta$-to-coil conformational transition depends on the ionization of the side chains.

\section{REFERENCES}

1. E. Peggion, A. S. Verdini, and E. Scoffone, Macromolecules, 2, 170 (1969).

2. E. Patrone, G. Conio, and S. Brighetti, Biopolymers, 9, 897 (1970).

3. A. Cosani, E. Peggion, A. S. Verdini, and M. Terbojevich, Biopolymers, 6, 1477 (1968).

4. M. Palumbo, A. Cosani, M. Terbojevich, and E. Peggion, Int. J. Biol. Macromol., 3, 91 (1981).

5. L. B. Crast, Jr., U. S. Patent, 3489750 and 3517023 (1970).

6. A. A. W. Long, J. H. C. Nayler, H. Smith, T. Taylor, and N. Ward, J. Chem. Soc. Sect C, 1920 (1971).

7. J. Noguchi, N. Nishi, M. Itaya, and S. Tokura, Kogyo Kagaku Zasshi, 69, 745 (1966).

8. J.-P. Vollmer and G. Spach, Biopolymers, 5, 337 (1967).

9. S. Beychok, "Poly- $\alpha$-amino Acids," C. D. Fasman, Ed., Dekker, New York, N.Y., 1967, p 293.

10. T. Miyazawa, "Polyamino Acids, Polypeptides and Proteins," M. A. Stahman, Ed., Academic Press, New York, N.Y., 1961, p 201.

11. S. N. Timasheff, H. Susi, R. Townend, L. Stevens, M. Gorbunoff and F. Kumosinski, "Conformation of Biopolymers," Vol. 1, G. N. Ramachandran, Ed., Academic Press, New York, N.Y., 1967, p 157. 